\title{
Comparison and development of sustainable office façade renovation solutions in the Netherlands
}

\author{
Michiel Ritzen ${ }^{\mathrm{a}, \mathrm{b}, *}$, Bertold vd Meijden ${ }^{\mathrm{a}}$, Ronald Rovers ${ }^{\mathrm{b}}$, Zeger Vroon ${ }^{\mathrm{b}, \mathrm{c}}$ and Chris Geurts ${ }^{\mathrm{a}, \mathrm{c}}$ \\ ${ }^{a}$ Eindhoven University of Technology, The Netherlands \\ ${ }^{\mathrm{b}}$ RiBuilT/Zuyd University of Applied Sciences, The Netherlands \\ ${ }^{\mathrm{C}} T N O$, The Netherlands
}

Received: 13 August 2013

Accepted: 14 November 2013

Abstract. Environmental, commercial and societal developments in the Netherlands stimulate the environmental improvement of the existing office building stock. In the Netherlands, about $15 \%$ of all office area was vacant in 2012, and the majority of offices have a relative poor energy performance. To measure the improvement, different assessment tools are applied. These tools either focus on one aspect, such as operational energy, and result in a specific outcome such as $\mathrm{MJ} / \mathrm{m}^{2}$, or these tools combine different aspects, such as energy and materials, through a weighted system and result in a generic outcome, such as 'excellent'. In this research, the relation between assessment outcome and actual environmental impact is investigated of both types of tools, by reflecting the outcome of the tool to the carrying capacity of a system. The relation is investigated through a comparison of the energy and material aspect of three office façade renovation solutions using four different assessment tools. Using a tool in which energy and material impact is related to the carrying capacity, current energy focused optimization might lead to a sub optimization of actual environmental impact. To illustrate this, a calculated façade solution is presented with minimal environmental impact based on carrying capacity.

Keywords: Façades, building materials, office buildings, environmental impact

\section{Introduction}

Between 1990 and 2005 global final energy consumption increased by $23 \%$ and $\mathrm{CO}_{2}$ emissions increased with $25 \%$ ((IEA), 2008). This consumption is expected to grow with another $45 \%$ between 2002 and 2025 (Ko \& Widder, 2011). 20\% to 40\% of this global energy consumption is consumed in the built environment (Pérez-Lombard, Ortiz, \& Pout, 2008), for more than $86 \%$ based on fossil fuels ((USEIA), 2011). Between 1995 and 2005, extraction of fossil fuels increased with 24\% (Bruckner, Giljum, Lutz, \& Wiebe, 2012). To lower overall energy consumption in the built environment and to lower dependency on fossil fuels, it is agreed within the EU that by the end of 2020 all new buildings are nearly zero-energy buildings, and that by the end of 2018 all new buildings occupied and owned by public authorities are nearly zero-energy buildings (NZEBs) (EU, 2010). NZEB means that the building has a very high energy performance and that the low amount of energy required should be generated to a very significant extent from renewable sources, on-site or nearby, having a

\footnotetext{
${ }^{*}$ Corresponding author: Ir. Michiel Ritzen, Eindhoven University of Technology/Zuyd University of Applied Sciences, The Netherlands. E-mail: m.j.ritzen@tue.nl.
} 
connection to the grid to cope with seasonal differences (AgentschapNL, 2012; EU, 2010; Torcellini, Pless, Deru, \& Crawley, 2006). Reaching the target of nearly zero energy depends only on improving the energy efficiency in the operational phase of the building. This requires adding material to the building for thermal insulation, building services and energy generation products. Consequently, the realization of a less energy consuming built environment is largely depending on an increase of material consumption, and collateral increase of construction material extraction, resulting in an increase of the material related impact compared to the energy related impact (Ramesh, Prakash, \& Shukla, 2010). Worldwide, extraction of construction minerals increased between 1995 and 2005 with 30\% (Bruckner et al., 2012).

Besides improvement the energy performance of new buildings, improvement of the energy performance of existing buildings is increasingly being realized, amongst others in the office sector.

The Dutch office market, consisting of 52.2 million square meters, had a vacancy percentage of $14.6 \%$ in 2012 (Zadelhoff, 2013), corresponding with 7.62 million square meters. As the market situation of office buildings in the Netherlands is not in equilibrium, renters have a wide variety of real estate to choose from, and are in the position to select offices with a high energy performance. The average energy label of the $10 \%$ of offices in the Netherlands that have an energy label is E (AgentschapNL, 2010a). This label corresponds with an operational energy performance of $1.49 \mathrm{GJ} / \mathrm{m}^{2}$.a for heating and cooling, lighting and hot tap water. Besides this market development, the Dutch government agreed that the Dutch government itself, responsible for around $20 \%$ of office space occupation in 2010 (AgentschapNL, 2010b), only rents offices with minimum energy label C since 2010, which results in a higher energy performance of buildings (AgentschapNL, 2010a). Already a number of NGO's and companies have joined this agreement, and it is expected that more organizations will join this government agreement in the framework of Corporate Social Responsibility (CSR). As a result, many offices are renovated to improve their energy label to a minimum of $\mathrm{C}$. In these renovations, the façade is often replaced to improve the operational energy performance of the building.

Currently, a wide range of tools is available to calculate the operational energy performance of buildings, such as the Dutch standard Energy Performance Calculation Program ((NEN), 2010), and VABI 114 (VABI, 2013).

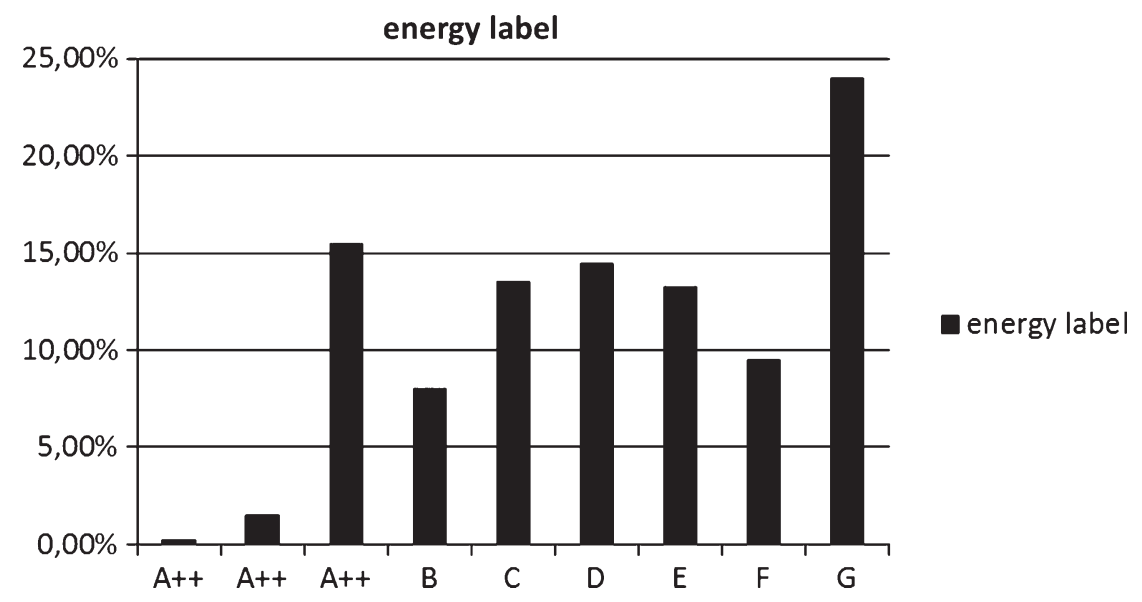

Fig. 1. Energy label distribution in the Dutch office market 2010 (AgentschapNL, 2010a). 
But assessment tools, used to measure the environmental impact of buildings, should take both the energy aspect and the material aspect in such a way into account that the necessary insight is created in the total burden. Examples of these tools are BREEAM, LEED and the Dutch Greencalct. In these tools, aspects such as energy and materials are combined with aspects such as management through a weighted combination of indicators (Häkkinen, 2012).

These tools have a number of advantages, such as the distinction in the level of sustainability of a building compared to other buildings, providing a communication tool, encouraging stakeholders to define sustainability requirements, and providing a vehicle for policymaking (Tran, 2009).

However, in these tools energy and materials account for different shares in total building performance outcomes and different categories are applied. The different categories are divided into different subcategories and the grading of the subcategories depends on different quantitative and qualitative parameters. The parameters are based on performance and evaluation, while different system boundaries are used and different levels of detail are applied. Resulting in an outcome in which the level of sustainability for comparable buildings differs due do the different aspects and weighting (Häkkinen, 2012). According to Iwaro et al, the measurements and the weights that should be given to the criteria are unresolved issues (Iwaro, Mwasha, Williams, \& Zico, 2014). The outcomes in the end might show how the energy and/or material situation has improved, but create a dilemma with regard to what the connection is between the outcome of the assessment tool and the actual environmental impact of the building.

Considering the material aspect, it is often only translated in embodied energy: the amount of energy necessary to process raw materials, modify materials and transport materials. Energy, embodied in buildings, may account for up to $60 \%$ of total life cycle energy (Dixit, Fernández-Solís, Lavy, \& Culp, 2012). Façades may account of up to $26 \%$ of total building embodied energy (Thormark, 2007; Yohanis \& Norton, 2002). The embodied energy in materials can be seen as a 'rebound effect' of energy performance improvement, and has in current practice a negative impact on the calculated operational energy performance improvement in household heating and cooling (Herring, 2009). The same can be expected in office buildings. By calculating material consumption using only the embodied energy, the operational energy aspect and the material aspect are translated in a corresponding quantity; energy. For instance, Belgian residential low energy buildings with a primary energy consumption for heating of ca. $900 \mathrm{MJ} / \mathrm{m}^{3}$ building volume over 30 years have a total embodied energy of $1400 \mathrm{MJ} / \mathrm{m}^{3}$ building volume over 30 years, which is higher than the energy consumption for heating (Verbeeck \& Hens, 2010).

For embodied energy calculations various definitions, methodologies and system boundaries are used (Dixit et al., 2012). An example of the latter is that there is a distinction between methodologies in which only the amount of fossil based energy is part of the calculation as it is 'added' to the product, and methodologies in which the total amount of embodied energy, both fossil based and renewable based, which comes from 'natural sources' such as the sun, is calculated. Besides the different calculation methodologies, most results have uncertainties due to temporal, spatial and technical circumstances (location, weather, societal and energy generation), which are in many cases not shown in databases underlying the calculation tools (Dixit et al., 2012). A third aspect of embodied energy calculations is the varying system boundary of the calculation.

All these aspects have resulted in databases which face the problem of incomparability and variation (Dixit et al., 2012). Besides these considerations, all embodied energy methods do not take into account the actual availability of resources, both renewable and non-renewable. As the extraction of construction materials increased significantly, it is worth exploring a method to be able to assess 
energy and materials equally. Due to the increase of material consumption and due to the associated increase of raw materials extraction more and more land is needed, with a negative impact on amongst others ecological systems, biodiversity and the reflectiveness of Earth (planetary albedo). In addition, raw materials which are necessary for the production of the building materials, such as copper, do not have an infinite stock. Besides land use required for extracting raw materials, there is also land needed for generating non-renewable and renewable energy to convert the raw materials in building materials or components and transportation of these building materials and components. As we have a limited amount of land and potential productivity of this land, it seems logical to base our consumption pattern on the land available for production and extraction of (building) materials, generation of energy, water production and food production.

In future, land necessary to produce renewable energy might compete with land necessary for food production and material production, which may lead to other choices in the design and realization of buildings (Rovers, de Flander, Gommans, \& Broers, 2011). Consequently, sustainability needs to be based on what can be generated and consumed in equilibrium within the system, implying an indicator based on the carrying capacity necessary to materialize and operate a function, instead of on impact calculations without any relation with the system itself (Rovers, 2010). The carrying capacity is the maximum persistently supportable load of a system (Catton Jr, 1986), and can be indicated by the amount of land necessary to sustain the functioning of the system and the time this land is necessary, embodied land.

To calculate the embodied land, an assessment tool called MAXergy is under development (Rovers, 2010). The embodied land of a product (in $\mathrm{m}^{2}$.year) indicates the amount of land needed for the extraction of raw materials, the growth of materials, the generation of power, the recuperation of land, etc. in the Dutch situation (Rovers, 2010, 2011; V. Rovers et al., 2011). The aim of the tool is to generate insight in the interaction of the energy and material aspect in buildings and relate the total impact of these impacts to the carrying capacity. In the methodology section this tool is further explained.

In this research, the relation between building environmental assessment tool outcomes and actual environmental impact is investigated. The energy and material aspects of three office façade renovation solutions are compared by using four different assessment tools in relation to the carrying capacity. A comparison is made between the situation before and after renovation of a south facing simulated office space with the different façade renovation solutions, covering the energy use of the building (operational energy), materials of the façade (embodied energy) and the related land use (embodied land) and compared with the outcome of a generic tool. Based on the comparison, a façade renovation solution with lowest environmental impact on carrying capacity has been calculated.

\section{Methodology}

The environmental impacts of three façade renovation solutions, realized in the Netherlands, have been investigated through a comparison of the outcomes of four different assessment tools before and after renovation.

For this research, a south orientated office space has been simulated in front of which different façade renovation solutions have been placed. The south facing façade has been selected because it is the building component which has the biggest effect on the annual cooling and heating load of a building in the Netherlands. The simulated space has a width of $8 \mathrm{~m}$, a length of $8 \mathrm{~m}$ and a height of 
$7 \mathrm{~m}$. The simulated space consists of office spaces divided over two floors, because office spaces are the most relevant spaces in the buildings and the design of one of the selected projects is based on two floors. The selection of the three office façade renovation projects was based on availability and completeness of data and drawings and the sustainability ambitions in Greencalc+.

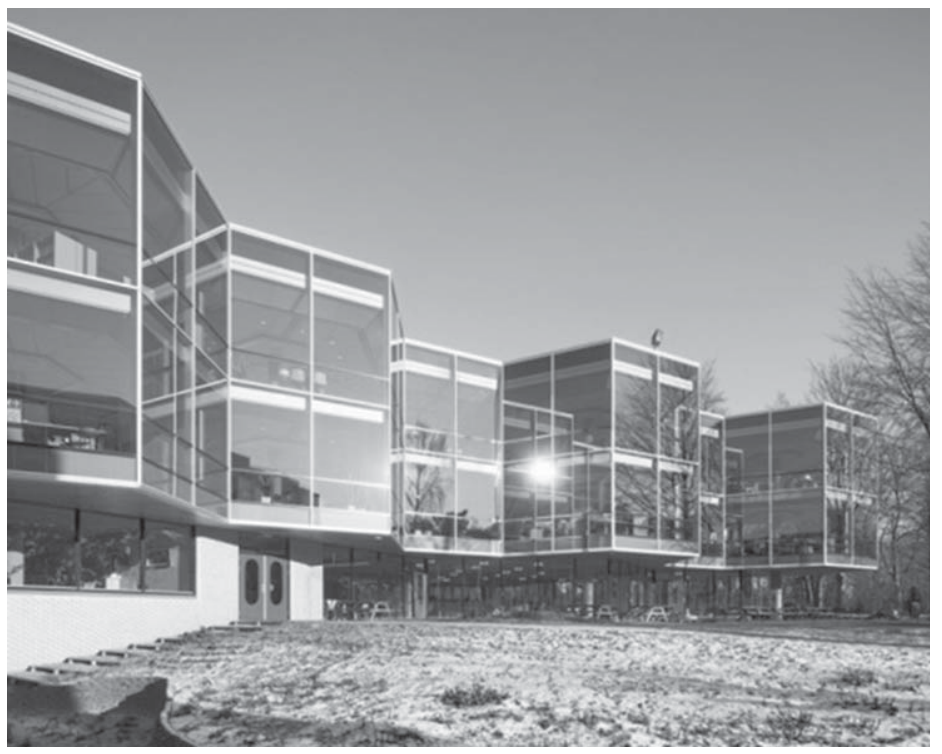

Fig. 2. Impression of the selected façade renovation solution of the DHV office building (source: vd Meijden).

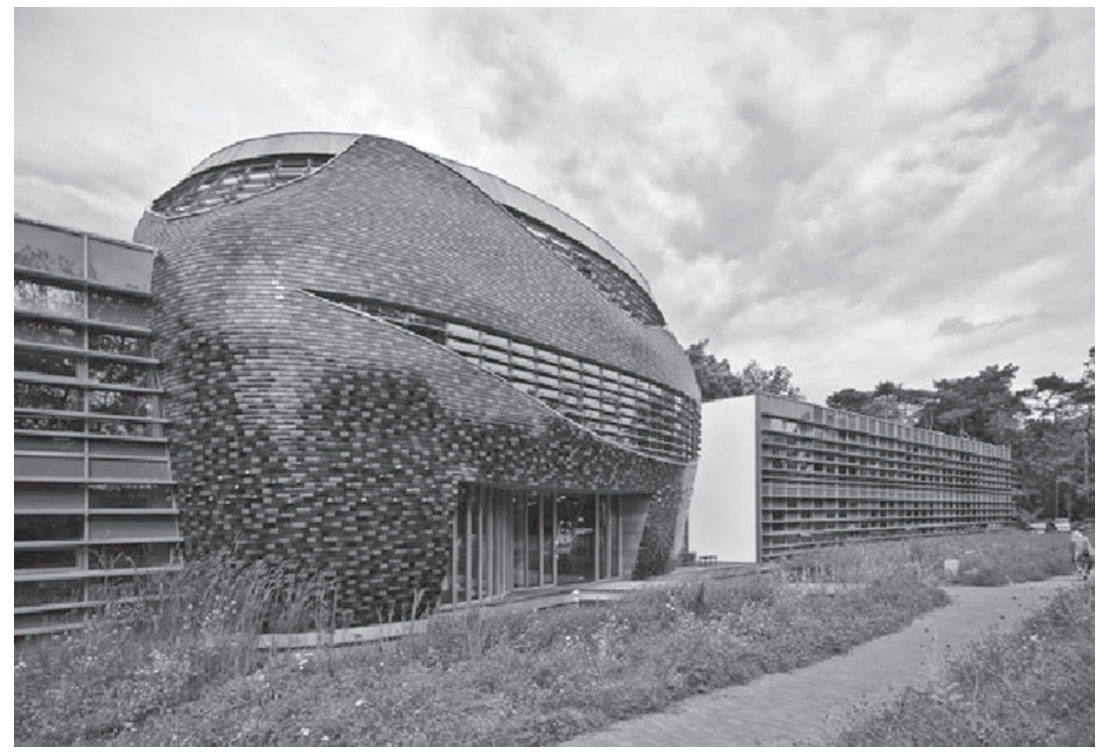

Fig. 3. Impression of the selected façade renovation solution of the WNF office building (source: vd Meijden). 


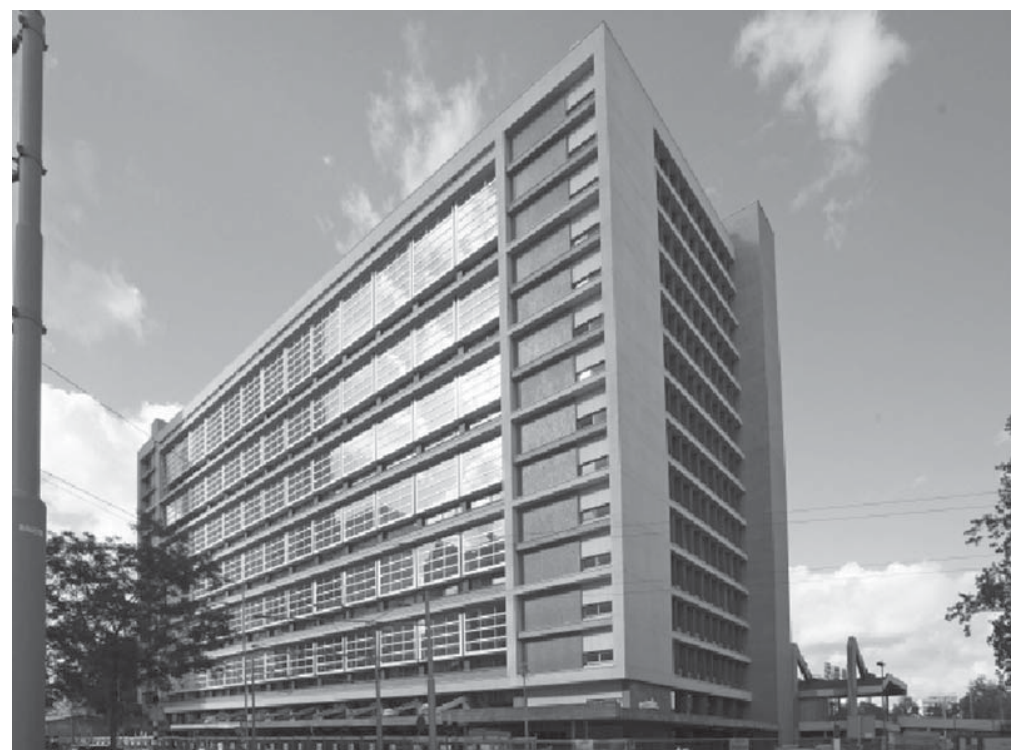

Fig. 4. Impression of the selected façade renovation solution of the Central Post office building (source: vd Meijden).

The following façade renovation solutions were selected:

- DHV office, Amersfoort; renovation during which the façade was totally replaced and the interior was preserved largely.

- WNF office, Zeist; renovation during which the façade was totally replaced and the building was partially demolished, stripped and refurbished.

- Central Post, Rotterdam; renovation of an existing post office, during which the façade was partially replaced.

For each simulated space the same technical installations were applied for a relevant comparison of the influence of the façades on assessment tool outcomes. In all cases, only the material and energy aspect of the façade was taken into account. Building structure and architecture, services, lighting, interior components, economic, societal and user behaviour were out of the scope of this research to generate in depth insight in the relation between the energy and the material aspect, although these other aspects might have a substantial influence on building performance and impact (Stephan, Crawford, \& de Myttenaere, 2012). For the calculations of the office façades a technical lifetime of 30 years (Ebbert, 2010) was chosen as reference. Energy and material aspects related to the pre-building phase as well related to the re-use phase and demolition phase were out of the scope of this research. In Table 1 an overview is given of materials used in the different façade renovation solutions.

Table 1

Overview of materials applied in the selected office façade renovation solutions

\begin{tabular}{ll}
\hline DHV office & aluminium curtain wall; double pane argon filled glazing \\
WNF office & wooden curtain wall, triple pane krypton filled glazing \\
Central Post office & aluminium curtain wall; double pane argon filled glazing
\end{tabular}


The office façade renovation solution with lowest environmental impact in terms of embodied land has been further optimized using MAXergy, because this tool relates most closely to carrying capacity and assesses both the material and energy aspect and its interaction without weighting.

The following assessment tools/databases have been applied: VABI, ICE, Greencalc+, and MAXergy and will be further introduced in the following sections.

\section{1. $V A B I 114$}

VABI 114 (VABI, 2013) is a dynamic building simulation program in which the annual heating and cooling load in MJ can be calculated. VABI 114 generates in depth insight in the operational energy aspect in relation to the indoor climate. VABI 114 complies with national and international standards BRL 9501, BESTEST, EDR according to ISSO 54 and ASHRAE standard 140. In this research, the program has been applied to calculate the operational energy demand of the simulated space with different façades before and after renovation. The program only takes operational energy into account. Other aspects, such as embodied energy, are not embedded in the program nor is the interaction between different aspects.

\subsection{ICE database}

In this research, the "Inventory of Carbon \& Energy" (ICE) database of the University of Bath (Hammond, 2008) is selected to calculate the embodied energy of the different façade renovation solutions before and after renovation. The ICE database has been selected because the data corresponds most closely to the Dutch situation. The ICE database is an inventory of the embodied energy of materials data, originating from Life Cycle Analyses (LCA's), books and papers. In the embodied energy calculation there is no interaction with other aspects such as operational energy.

\subsection{GreenCalc+ program}

GreenCalc+ (Greencalc+, 2013) expresses the sustainability of a building in an environmental index. The environmental index of a building (Milieu Index Gebouw - MIG) is based on a comparison of the environmental costs of material consumption, energy consumption, and water consumption with the environmental costs of a standard Dutch building realized in 1990. Greencalc+ has been applied to determine the overall building sustainability after renovation. By translating all aspects into one cost aspect they can be combined to one generic outcome and thus compared to other buildings. The determination of environmental costs of materials is based on CML-2, the LCA method developed by the University of Leiden, in combination with the Eco-indicator '99 method and the TWIN-model. The method of Müller-Wenk is used for the determination of transportation related noise disturbance. The determination of environmental costs is based on the Dutch standards NEN 2916:2004 and NEN 5128:2004, complying with the Dutch standard Energy Performance Calculation. This calculation is through a LCA translated into environmental costs. For office buildings, the determination of water consumption is calculated with the Dutch 'Water Performance Standardisation'. This calculation is through a LCA translated into environmental costs. Although the impact of user mobility is calculated in Greencalc+, it is not part of the generic outcome. The user mobility is determined for office buildings 


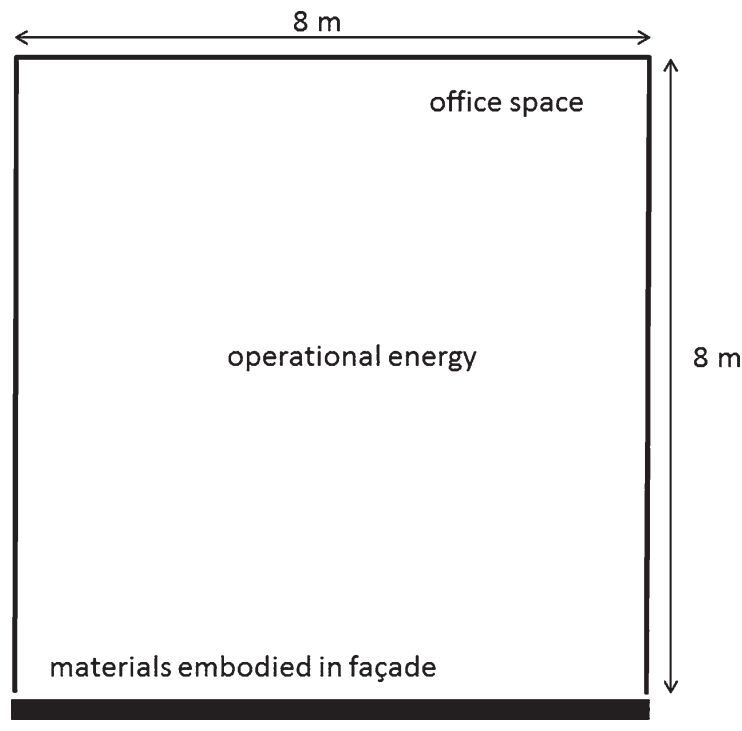

Fig. 5. Floor plan of the investigated simulated south facing office space.

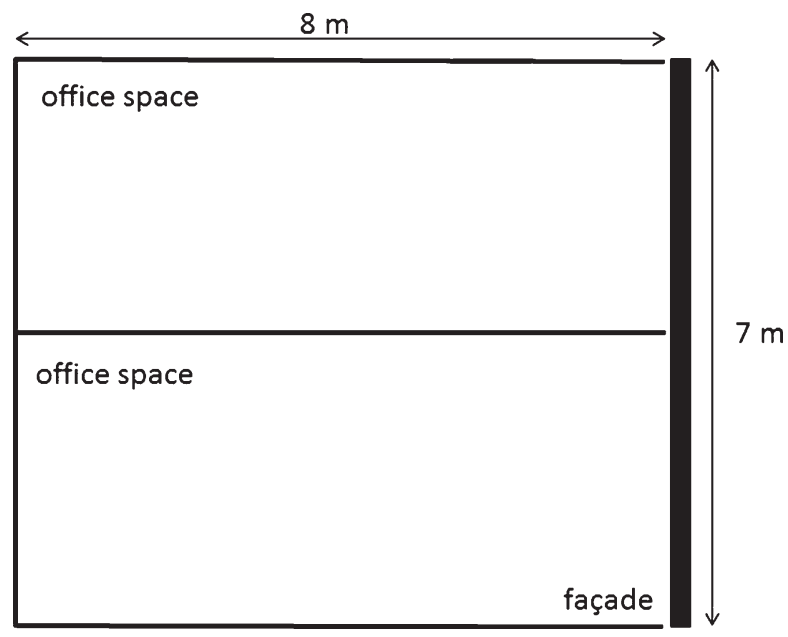

Fig. 6. Section of the investigated simulated south facing office space.

by a calculation in an adapted version of the software program VPL-KISS (Greencalc+, 2013). Between the different aspects in Greencalc+ there is no interaction or interrelation.

The standard reference building from 1990 has a value of 100 MIG. When a building is more sustainable than the reference building from 1990, then the value becomes above 100 MIG. Buildings with a MIG-value below 100 are less sustainable than a building realized in 1990. Although this tool indicates the relative improvement of environmental impact of a building compared with other buildings and with a building in 1990, it does not indicate clearly the actual impact on the environment. 


\subsection{MAXergy}

MAXergy is a sustainability tool which expresses the energy and material impact of a project in the same physical quantity: Embodied land. Embodied land is the amount of space and time necessary to fulfil the energy and the material demand for a certain function in a certain environment. Embodied land is expressed in $\mathrm{m}^{2}$.year (Rovers, 2011). The embodied land of the different façade renovation solutions before and after renovation has been calculated using MAXergy. The total embodied land (EL) of a product is calculated using several databases as input the amount of new and recycled materials. The total embodied land calculation can be divided into direct embodied land (land and time required for the creation of a raw material), indirect embodied land (embodied energy converted into land and time) and operational energy (converted into land and time).

The embodied land for a building consists of three components, a. EL building, b. EL materials and c. EL operational energy, as indicated in Fig. 7.

a. EL building indicates the land occupied by the building during its lifespan itself and can be directly derived from the design drawings in $\mathrm{m}^{2}$.

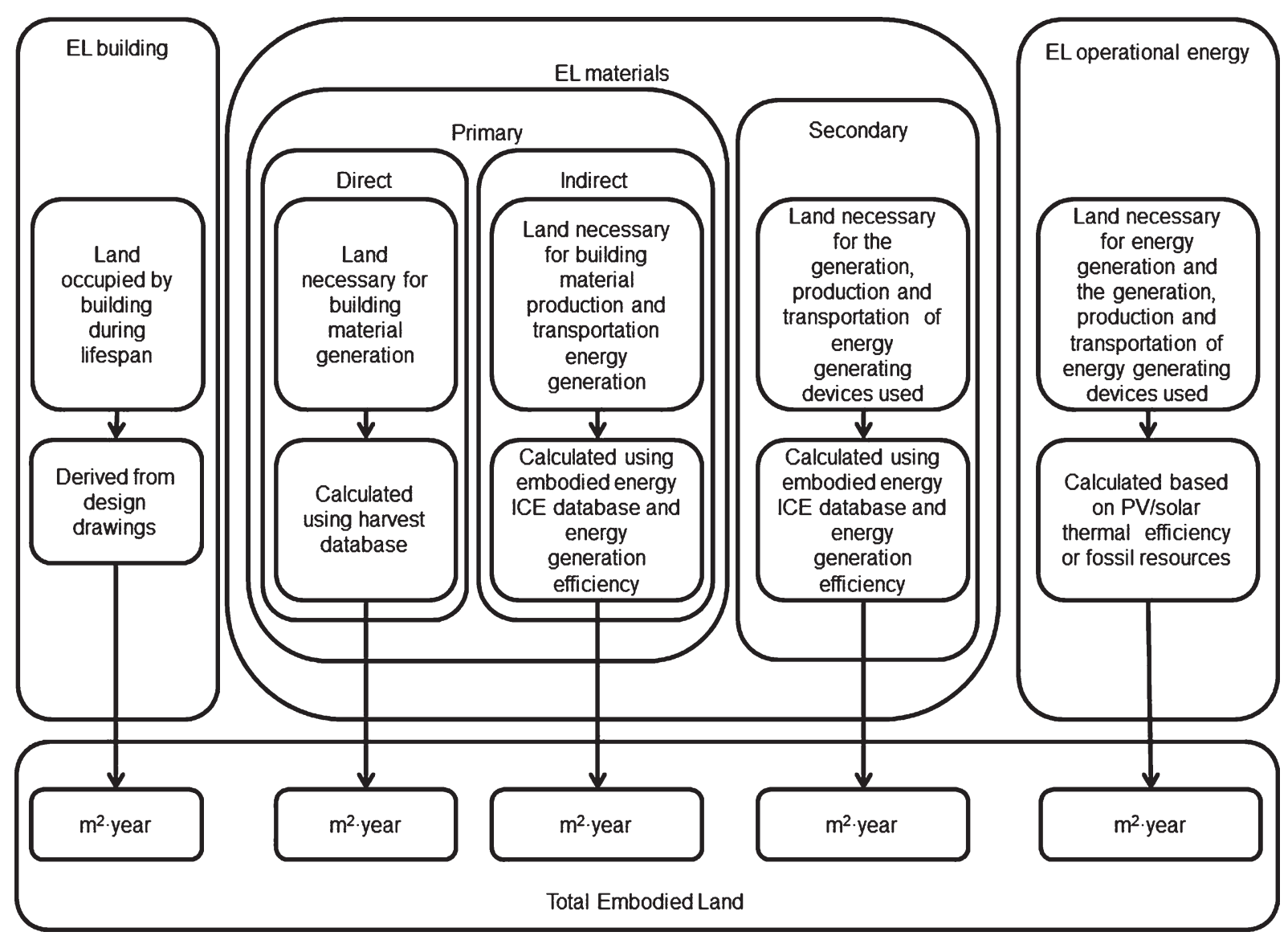

Fig. 7. Schematic overview of the proposed embodied land calculation method for a combined environmental assessment of energy and materials in the built environment. 
b. EL for materials consists of two impacts: The primary impact indicates the time-land required to generate, produce and transport the material itself. The primary impact consists of the direct EL for material generation, and indirect EL for material production and transportation.

1. The direct primary EL is calculated using a harvest database in which harvest $/ \mathrm{m}^{2}$ are collected, depending on the origin of the material. The indirect primary EL is based on the ICE embodied energy database and through energy generation surface calculated (solar or fossil based) (Hammond, 2008). The input needed to calculate both direct and indirect primary EL is the mass of the building material $(\mathrm{kg})$ and energy generating device efficiency.

2. The secondary impact indicates the time-land required to generate and produce the techniques and installations necessary to generate the materials; e.g. the photovoltaic panels required to generate the necessary embodied energy. The tertiary impact and other possible relevant impacts, such as operational transportation energy, are not taken into account (Stephan, Crawford, \& de Myttenaere, 2013). The input needed to calculate the secondary EL is both the mass of materials used in the installations $(\mathrm{kg})$ and installation efficiency $\left(\mathrm{W} / \mathrm{m}^{2}\right)$.

C. EL operational energy consists of the land necessary to generate the energy using solar energy (PV/ solar thermal) or fossil resources and the EL necessary for the generation, production and transportation of the materials used for the energy generating devices.

These tools and databases were selected to generate in depth insight in the operational energy and material aspect (VABI 114 and ICE database), and to be able to compare these results with a widely used generic tool in the Netherlands (Greencalc+) of which the data of all cases was available, and to be able to relate this to the carrying capacity (MAXergy).

\section{Results}

In the following section, the calculated results of the different applied assessment tools/databases; VABI 114, ICE database, Greencalc+ and MAXergy are presented. In Section 3.2.1 the results of VABI 114 and the ICE database are combined.

\section{1. $V A B I 114$}

Figure 8 shows the results of the annual cooling and heating load of the simulated office space with different façade solutions before and after the renovation, calculated with VABI 114. The heating and cooling load of all three cases after the renovation is similar. The cooling load of the investigated south orientated space is in all buildings the largest energy factor both before and after the renovation. The renovation of the façade has mainly impact on the heat load of the building, which is strongly reduced after the renovation. This is achieved by increasing the Rc value of the façade through the application of materials with higher values of thermal insulation and the application of double pane argon filled glazing or triple pane krypton filled glazing.

\subsection{ICE database}

Figure 9 shows the results of all embodied energy calculations of the different façade solutions before and after the renovation. The embodied energy required for the façades of the DHV office 
M. Ritzen et al. / Comparison and development of sustainable office façade renovation solutions in the Netherlands 63

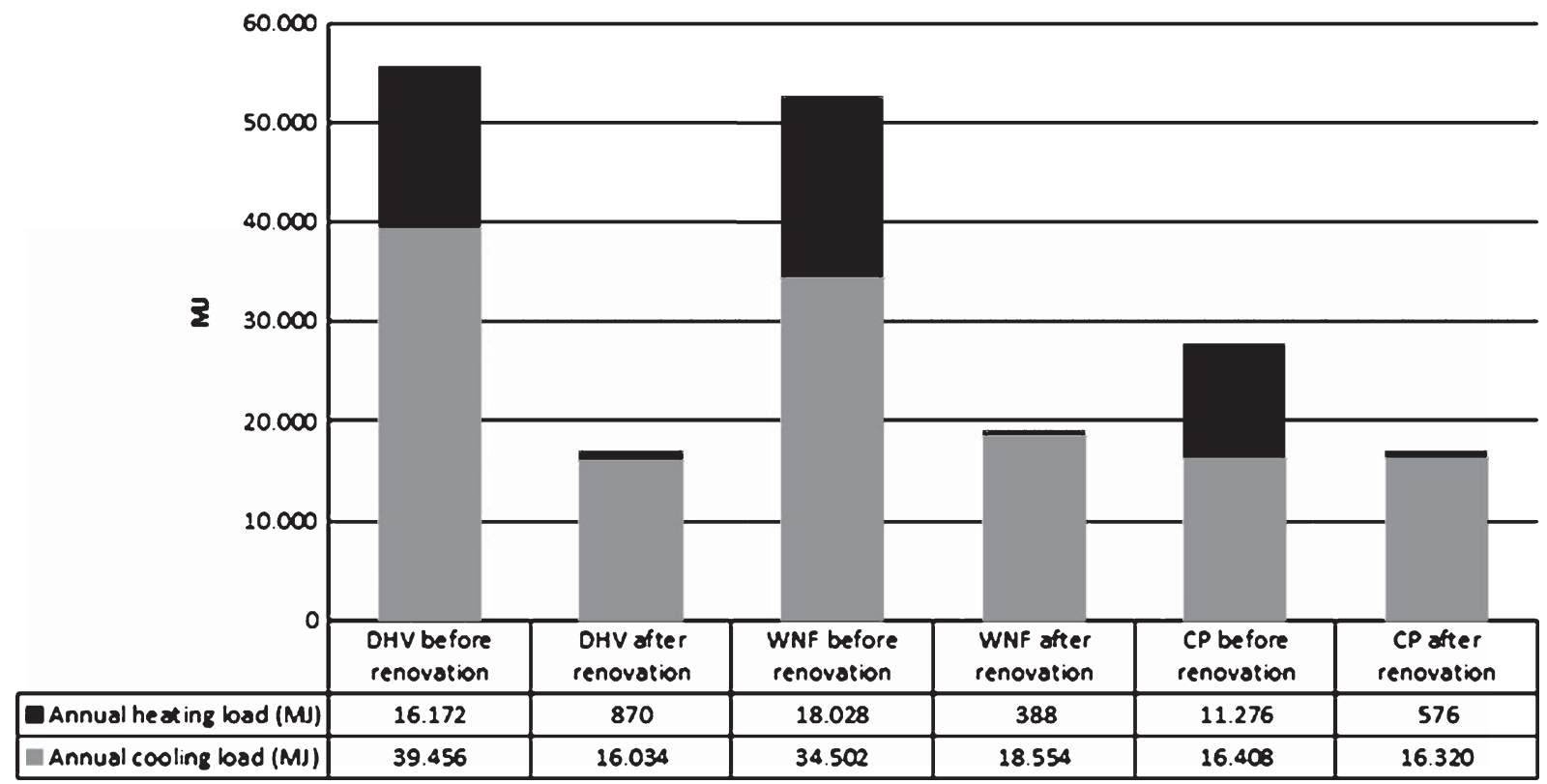

Fig. 8. Annual operational energy load consisting of heating and cooling of the simulated south facing office space with façade solutions before and after renovation.

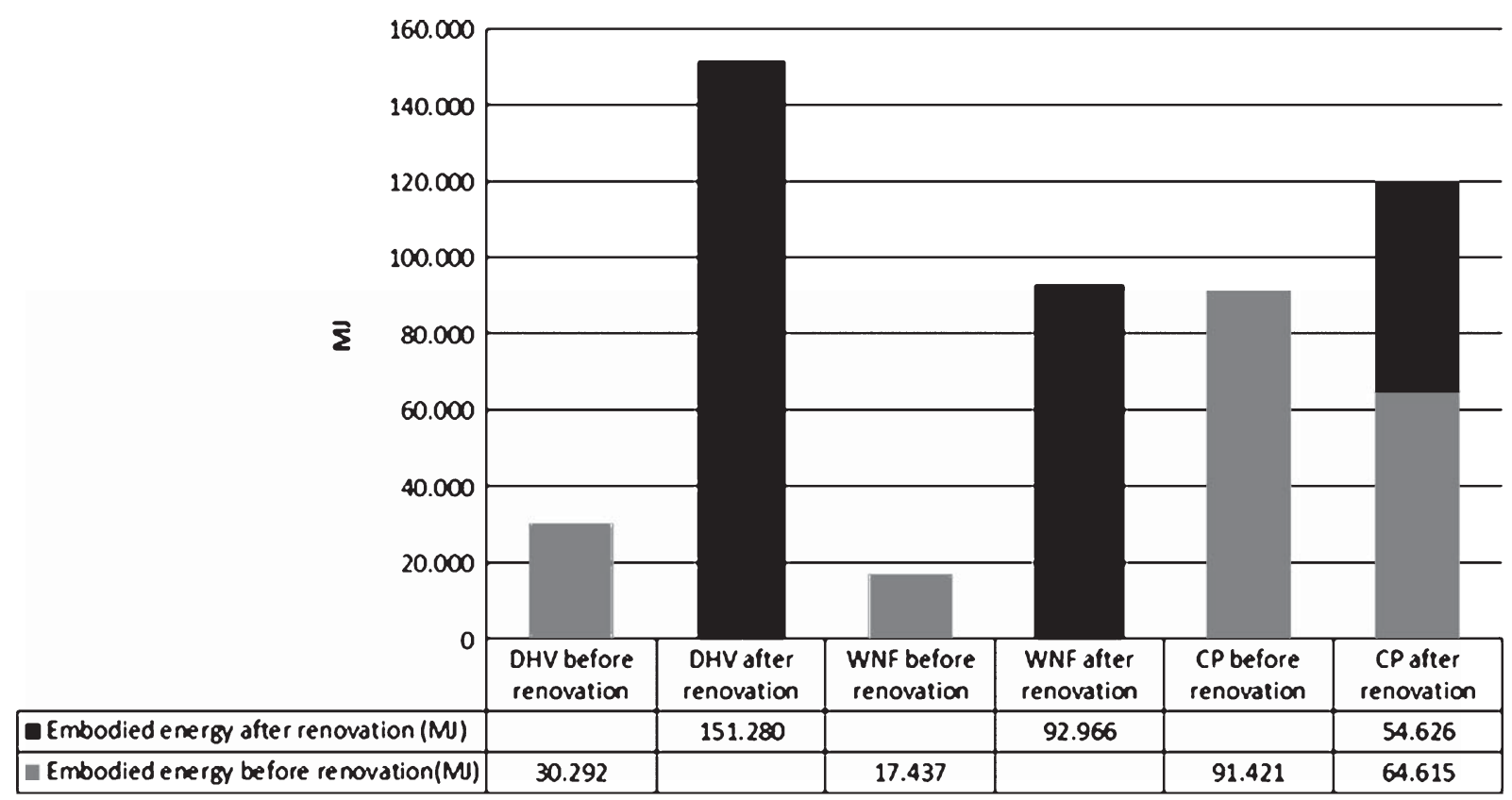

Fig. 9. Total embodied energy of the façade solutions before and after renovation.

and the WNF office after the renovation is many times higher than the embodied energy of the façades before the renovation. After renovation, the DHV office has a new aluminium curtain wall with double pane argon filled glazing and the WNF office has new wooden curtain wall with triple 


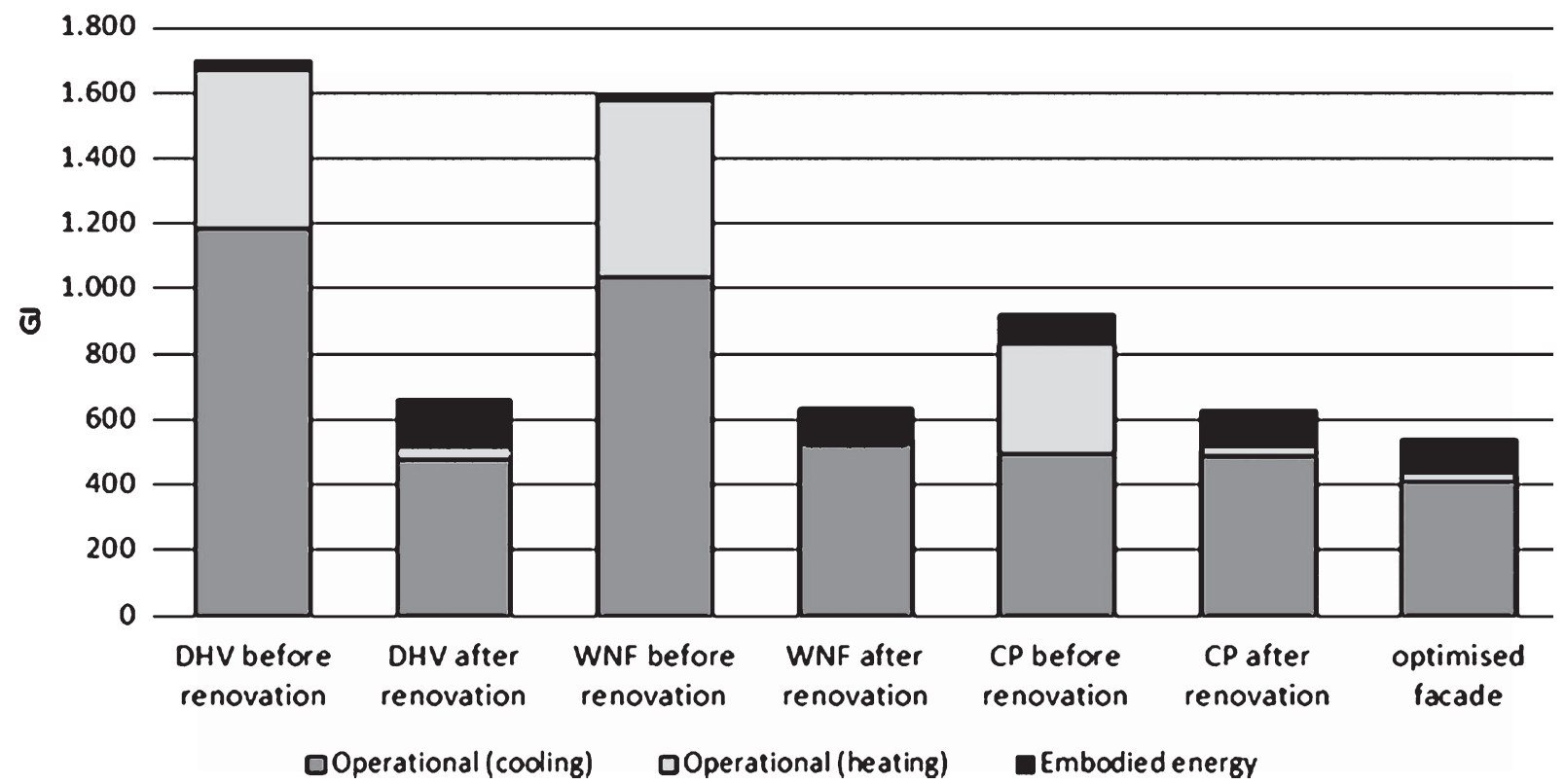

Fig. 10. Total energy performance of the simulated south facing office space with façade solutions before and after renovation, over 30 years.

pane krypton filled glazing. The embodied energy required for the new façade of the Central Post building is relatively small compared to that of the other buildings. This is because this façade was only partly replaced and remained largely unchanged. Furthermore, the embodied energy required for the original façade was already very high due to the large amount of the materials applied, such as concrete and steel. The existing aluminium façade with single glazing is replaced by a new aluminium façade with double pane argon filled glazing.

\subsubsection{Combination of VABI 114 and ICE database}

In Fig. 10 the results of total energy consumption calculations are shown (operational energy of the simulated office space and the embodied energy of the façade) before and after the renovation, for a total technical lifetime of 30 years. The results indicate that, for the investigated south facing office space, the cooling load has the largest energy impact, both before and after the renovation. It also shows that the heat load of the office space has decreased significantly after the renovation, which is the result of the improved thermal properties of the façades after the renovation. To achieve these improved thermal properties more embodied energy is required for the façades. In general the embodied energy of the façades increases after renovation, but the cooling load remains the largest energy demand for this south facing office space.

\subsection{GreenCalct}

The results of all renovation projects in Table 2 show a final score above 200 and all projects score both in the field of energy performance and material consumption an A, which is good. In the results there is no difference between the various projects in the field of energy performance and material 
Table 2

Greencalc+ score of all renovation projects

\begin{tabular}{lccc}
\hline & DHV office & WNF office & Central Post office \\
\hline Material & A & A & A \\
Energy & A & A & A \\
Water & E & F & G \\
Total & 239 & 269 & 252 \\
\hline
\end{tabular}

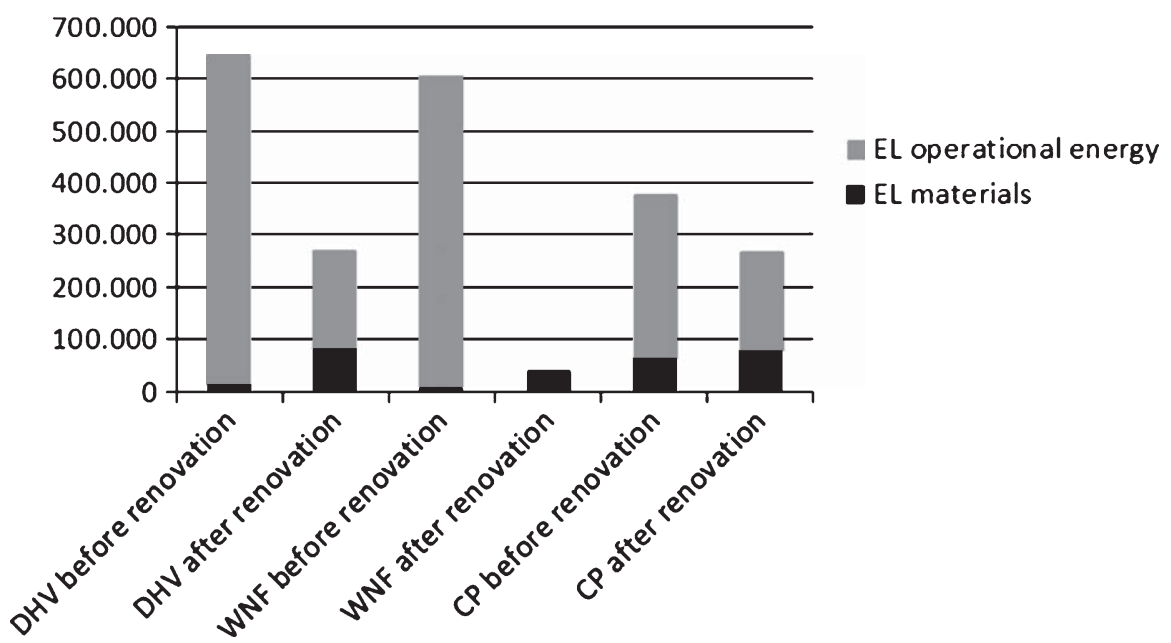

Fig. 11. Total embodied land in $\mathrm{m}^{2}$ of the simulated south facing office space with different façade solutions before and after renovation based on fossil fuels, over 30 years.

consumption. The WNF office has the highest total score, because the building generates energy with photovoltaic (PV) panels.

\subsection{MAXergy}

Figure 11 show the calculated embodied land of façade materials and the calculated embodied land of operational energy of the simulated office space when all energy required for the operational energy is based on fossil fuels. Fossil fuels have a significant larger EL that renewable fuels due to the large amount of land and large span of time necessary to generate these fuels (R. Rovers et al., 2011). Due to this, the embodied land of the operational energy is the determining factor compared with the embodied energy for the materials of the façade. Only the results of the WNF façade solution show a different situation where the material use is the determining factor. This is because after the renovation operational energy in this building is generated by solar energy.

Figure 12 shows the embodied land calculations of the simulated office space with different façade solutions before and after renovation, over 30 years, when all energy is generated by solar energy (solar panels and solar collectors). In this calculation, the total embodied land for all solutions is much smaller than with a similar calculation using fossil fuels, due to the large time-land impact to 


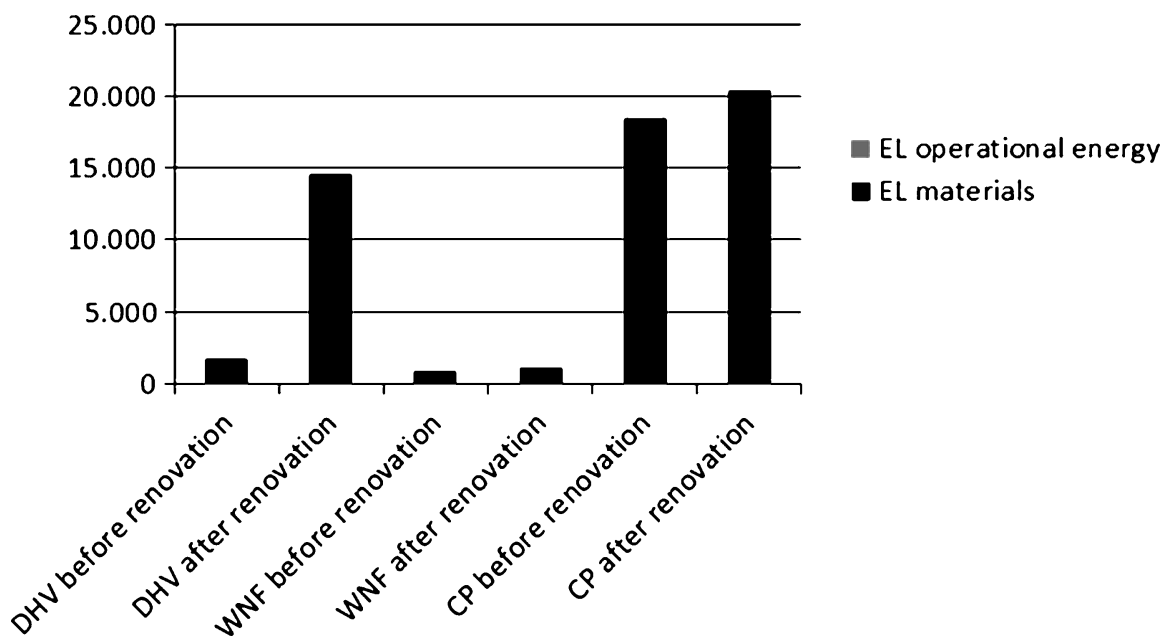

Fig. 12. Total embodied land in $\mathrm{m}^{2}$ of the simulated south facing office space with different façade solutions before and after renovation based on solar energy, over 30 years.

generate fossil fuels. Secondly, the embodied land for the façade materials is much greater than the embodied land for the operational energy. The embodied land of the operational energy is in most cases negligible compared to the embodied land of the façade materials.

The results show that the WNF office façade solution after renovation scores very good in comparison with the other façades. This façade consists mainly of wood, a natural material with low embodied energy. Natural (bio-based) materials score very well in the embodied land calculation, because these materials can grow back naturally by themselves, so a closed-loop system is created without adding energy.

A closed-loop system for the materials is created when a material that is used as a building product has grown back within the lifetime of the façade, and all energy to realize the building product has been regenerated. The aluminium, concrete and steel that are used in the DHV and the Central Post Office façade solutions are not bio-based and cannot grow back. These materials are however recyclable and partially reusable. The recycling percentages of these materials are not $100 \%$, for aluminium it is for instance $94 \%$ (Haas, 2002). According to the MAXergy calculation a lot of energy is needed to win back the non-recycled percentage of these materials.

\section{Calculation of a façade renovation solution with lowest environmental impact on carrying capacity}

Based on the results presented in section 3, the WNF façade solution has been further investigated and its environmental impact has been further minimized using MAXergy. As indicated in the preceding sections, using only energy related calculations or using a generic assessment tool does not offer a comprehensive carrying capacity based indicator of the environmental impact of a building. Analysis of the materials applied in the WNF façade solution (Fig. 13) shows that most of the embodied land of the façade originates from non bio-based materials, such as steel and aluminium. 
Based on this analysis a comparison has been made between four façade solution versions to investigate the embodied land minimisation as a result of the interaction of the material and energy aspect. In Fig. 14 an overview is given of these versions:

a. The façade after renovation with a certain amount of material related EL, mainly due to nonrenewable materials, and a certain amount of operational energy related EL;

b. Minimisation of material related EL while maintaining the same operational energy related EL resulting in a façade in which the actual openings are maintained and thermal insulation is maintained, but all materials are $100 \%$ bio-based.

c. Minimisation of material related EL, resulting in a façade consisting of a plywood sheet and no openings.

d. Minimisation of operational energy related EL with high insulation values for the opaque façade components $\left(\mathrm{Rc}=10 \mathrm{~m}^{2} \cdot \mathrm{K} / \mathrm{W}\right)$.

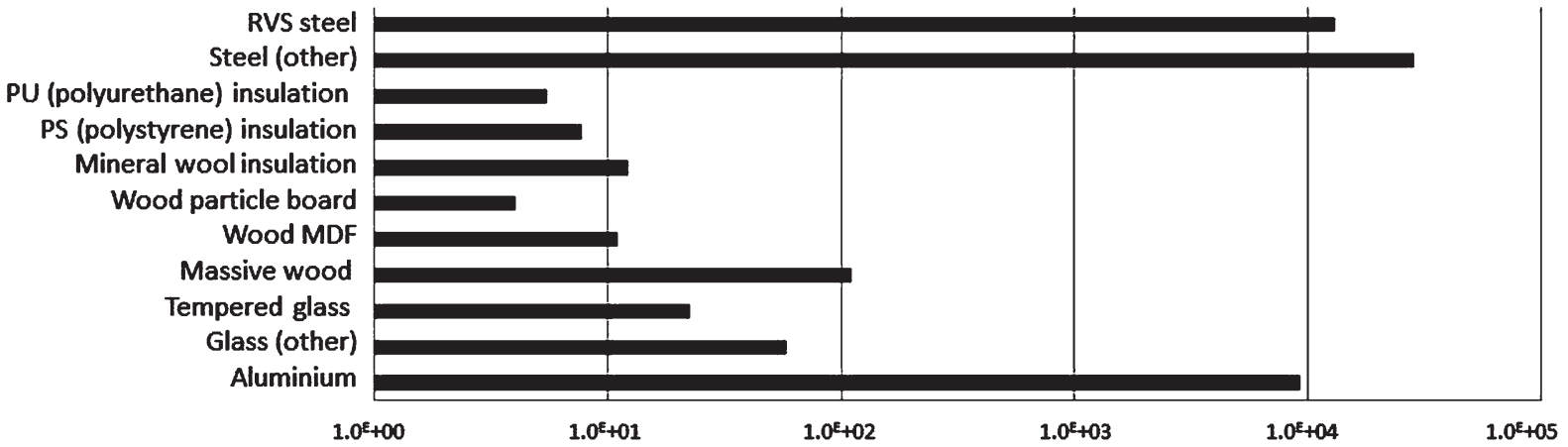

Fig. 13. embodied land of different materials in the WNF façade solution in $\mathrm{m}^{2}$.year.

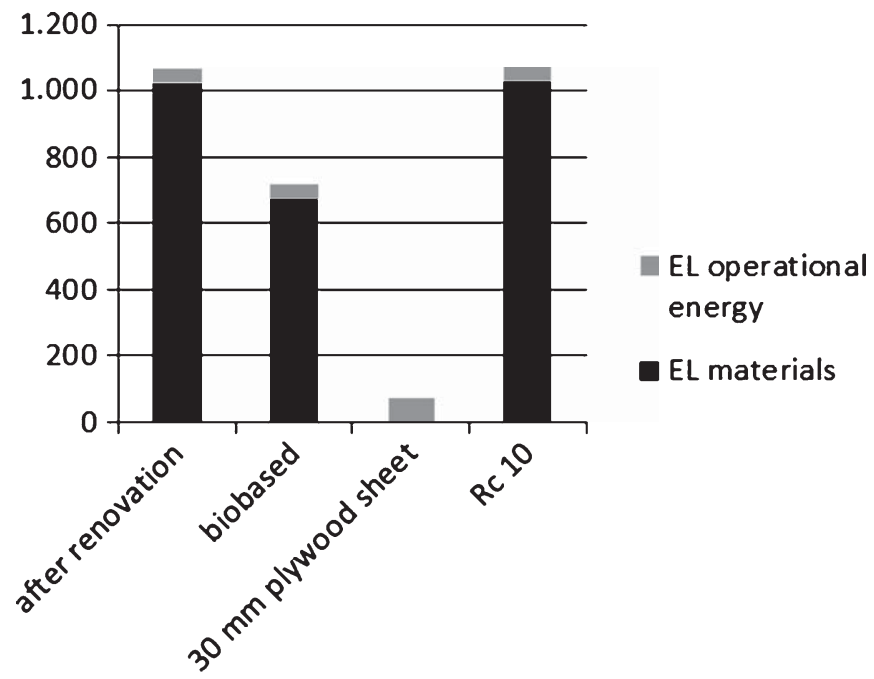

Fig. 14. Total embodied land in $\mathrm{m}^{2}$ of the simulated south facing office space with different façade solution versions based on solar energy, over 30 years. 


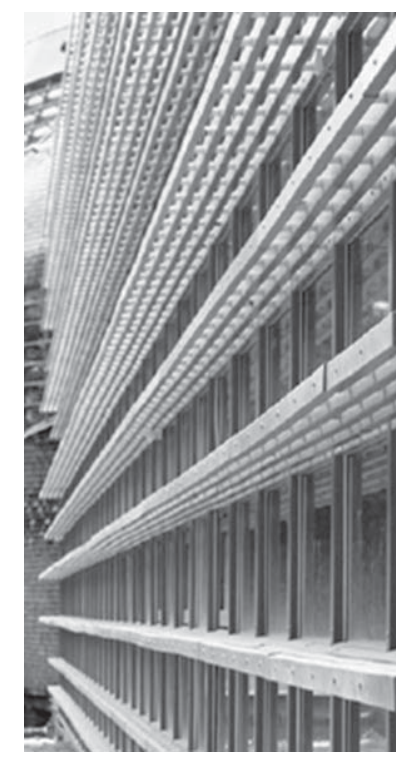

Fig. 15. Picture of the realized WNF façade renovation (source: vd Meijden).

In all versions the embodied land of the materials is still larger than the embodied land of the operational energy, indicating the importance of material consumption in this assessment method. Even when the façade consists of only a minimal amount of bio-based materials (only a $30 \mathrm{~mm}$ plywood sheet), the embodied land required for the operational energy is small.

Within the boundaries of the Dutch Building Regulation, a minimisation of environmental impact of the façade renovation solution has been investigated. The Dutch Building Regulations indicate the following for this office façade calculation:

- Insulation value for opaque façade parts $\mathrm{Rc} 3.5 \mathrm{~m}^{2} \mathrm{~K} / \mathrm{W}$.

- U value transparent façade parts $\mathrm{U} 2.2 \mathrm{~W} / \mathrm{K} \cdot \mathrm{m}^{2}$.

- $2 \mathrm{~m}^{2}$ transparent façade surface per office floor.

Within these boundaries a maximum use of bio-based materials is investigated. Non bio-based materials, like metals, need to be recycled as much as possible. The façade design consists for $93 \%$ of bio-based materials, in which the metal components have been replaced by fibre-reinforced composites. Even the design of window placing is realized without metal components (Fig. 16). Resulting in a façade solution that needs a total of $304 \mathrm{~m}^{2}$ embodied land for a lifespan of 30 years, which is a reduction of $70 \%$ compared to the actual WNF façade renovation solution. In addition, in the design is taken into account that the building components are easy to separate, increasing the possibilities for re-use and recycling. The collateral effect of this minimization of embodied land is a solution with disputable architectural quality, compared to the realized WNF office façade renovation design (Fig. 16).

\section{Conclusions and discussion}

Based on the comparison of the simulated south facing office with different façade renovation solutions and the calculation of a façade renovation solution with minimal environmental impact 


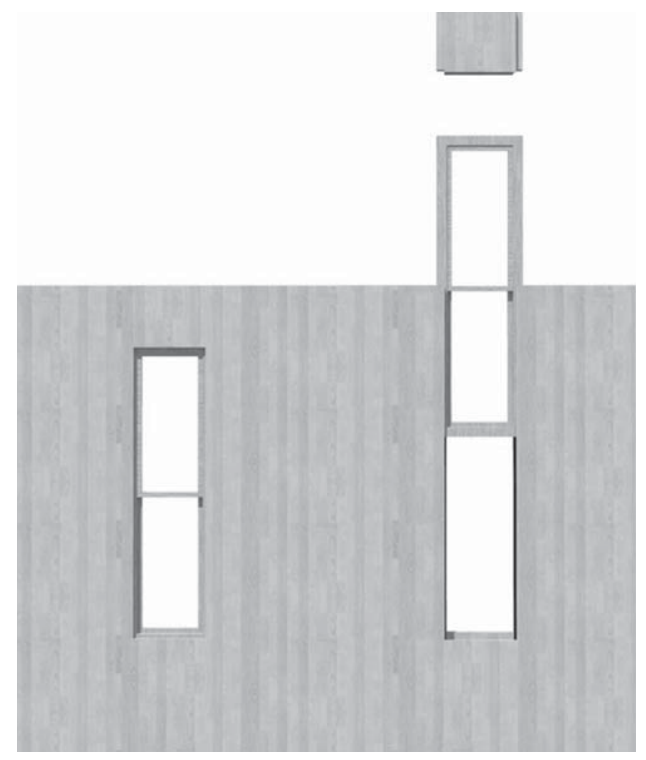

Fig. 16. Picture of the calculated office façade renovation with minimal embodied land (source: vd Meijden).

based on carrying capacity, the following conclusions concerning operational energy performance, material performance and the related embodied land are drawn.

- This research indicates that in the simulated cases operational energy efficient façade renovations result in a decrease of operational energy and an increase of embodied energy in the façade. Assessment tools based either on one aspect such as operational energy or on only energy related aspects or resulting in a generic outcome do not generate insight to lower the actual total environmental impact.

- In all cases, the cooling load is the largest energy part of total energy demand both before and after the renovation and the embodied energy of the façades is a small portion of the total energy demand, over a lifespan of 30 years, considering only a south facing façade. These results would presumably be different when the complete building would be taken into account and when other orientations of the façade would be investigated.

- Not only the amount of materials but also the choice of materials determines the embodied energy and embodied land of the façade.

- In the case of the WNF façade solution, the building itself generates after the actual renovation to a high extend its own energy through photovoltaic (PV) panels on the roof. If in this case the operational energy would not be included in the calculation and the PV panels would be included in the material calculation, the total energy consumption of the building would consist solely of embodied energy. Material consumption would in this case be the determining factor in environmental impact.

- The embodied land calculations based on fossil fuels show in almost all cases that the operational energy is the determining factor compared to materials. An exception is the WNF office façade solution after the renovation because in this case the operational energy of the building is generated on site. In this situation, the material aspect becomes the determining factor in environmental impact. 
70 M. Ritzen et al. / Comparison and development of sustainable office façade renovation solutions in the Netherlands

- The calculated office façade renovation solution indicates that the amount of materials and the choice of materials determine the environmental impact in nearly all situations. Bio-based materials, such as wood, score very well in this calculation because the low amount of embodied energy and renewability. Further research is suggested to compare the façade versions using other tools, and base façade versions on these tools.

- It can be concluded that in a combination of embodied and operational energy based on fossil fuels, the material aspect determines the environmental impact in the case of NZEB's, such as the WNF building, emphasizing a tool in which the material aspect and energy aspect are non-weighted assessed, and the MAXergy tool offers this possibility.

Based on this research project, the following conclusions concerning the MAXergy tool are drawn to suggest further research in this direction.

- The energy related embodied land calculation in MAXergy is based on the surface of solar panels and solar collectors, which is necessary for generating electricity and heat. The results of the embodied land calculations are therefore highly dependent on the efficiency of the solar panels and solar boilers used for this.

- Operational energy is in an increasing number of buildings generated with renewable sources, but the majority of embodied energy is not. Therefore, a comparison is made between the land use by means of fossil energy and solar energy. Further research into impact by using the current energy mix (fossil fuels, nuclear and renewable energy) is recommended to generate insight in the actual energy related embodied land of materials.

- An important part of the MAXergy calculation is the recovery of raw materials such as metals. In many cases this is the decisive factor for the final result. For the recovery of metals for example a method is chosen, in which metal particles are filtered from seawater. This includes a number of assumptions. Further research should be done on the recovery of metal particles.

- As the MAXergy tool aims at relating the combination of material consumption and energy performance of a building to the carrying capacity of a system it offers the possibility to generate insight in building performance from a perspective related to our planet. But as the tool is based on existing embodied energy data, the same discussions concerning availability of data, the bandwidth of results, etc. are relevant and further research should be conducted in order to generate more reliable outcomes related to the carrying capacity.

\section{References}

(IEA), Internation Energy Agency. (2008). Worldwide trends in energy use and efficiency.

(NEN), Nederlands Normalisatie Instituut. (2010). NEN EPW NPR 5129+ A2:2010v2.2 Energieprestatie van woonfuncties en woongebouwen - Rekenprogramma (EPW).

(USEIA), U. S. Energy Information Administration. (2011). International Energy Outlook 2011: U.S. Energy Information Administration.

Agentschap, N. L. (2010a). Onderzoek naar het energie- en $\mathrm{CO}_{2}$-reductiepotentieel Duurzaam inkopen van gebouwen, de Rijksgebouwendienst als voorbeeld.

Agentschap, N. L. (2010b). Rapport energiecijfers kantoren.

Agentschap, N. L. (2012). Nationaal Plan voor het bevorderen van bijna-energieneutrale gebouwen in Nederland.

Bruckner, M., Giljum, S., Lutz, C., \& Wiebe, K. S. (2012). Materials embodied in international trade - Global material extraction and consumption between 1995 and 2005. Global Environmental Change, 22(3), 568-576. doi: 10.1016/j.gloenvcha.2012.03.011

Catton Jr, W. R. (1986). The Gaia atlas of planet management: for today's caretakers of tomorrow's world: N. Myers (general ed.). Journal of Rural Studies, 2(2), 170-171. doi: http://dx.doi.org/10.1016/0743-0167(86)90061-6 
M. Ritzen et al. / Comparison and development of sustainable office façade renovation solutions in the Netherlands 71

Dixit, M. K., Fernández-Solís, J. L., Lavy, S., \& Culp, C. H. (2012). Need for an embodied energy measurement protocol for buildings: A review paper. Renewable and Sustainable Energy Reviews, 16(6), 3730-3743. doi: 10.1016/j.rser.2012.03.021

Ebbert, T. (2010). Re-Face: Refurbishment Strategies for the Technical Improvement of Office Facades. (PhD), Delft University of Technology, Delft.

EU Directive 2010/31/EU of the European Parliament and of the council of 19 May 2010 on the energy performance of buildings (recast) (2010).

Greencalc+. (2013). Greencalc+ website. from http://www.greencalc.com/

Haas, M. (2002). NIBE's basiswerk milieuclassificatie.

Häkkinen, T. E. (2012). Sustainability and performance assessment and benchmarking of buildings - Final report. Espoo: VTT.

Hammond, G. J. (2008). Inventory of Carbon and Energy (ICE). University of Bath, UK.

Herring, H. S. (2009). Energy Efficiency and Sustainable Consumption (H.S. Herring, Steve Ed.). Hampshire, England: Palgrave Macmillan.

Iwaro, J., Mwasha, A., Williams, R. G., \& Zico, R. (2014). An Integrated Criteria Weighting Framework for the sustainable performance assessment and design of building envelope. Renewable and Sustainable Energy Reviews, 29(0), 417-434. doi: http://dx.doi.org/10.1016/j.rser.2013.08.096

Ko, J., \& Widder, L. (2011). Building envelope assessment tool for system integrated design. Paper presented at the PLEA 2011, Louvain-laNeuve, Belgium.

Pérez-Lombard, L., Ortiz, J., \& Pout, C. (2008). A review on buildings energy consumption information. Energy and Buildings, 40(3), 394-398. doi: 10.1016/j.enbuild.2007.03.007

Ramesh, T., Prakash, R., \& Shukla, K. K. (2010). Life cycle energy analysis of buildings: An overview. Energy and Buildings, 42(10), 1592-1600. doi: http://dx.doi.org/10.1016/j.enbuild.2010.05.007

Rovers, R. (2010). O-material building: Space time analyses. Paper presented at the SB10, Maastricht, The Netherlands.

Rovers, R. (2011). MAXergy and embodied land. In RiBuilT (Ed.).

Rovers, R., de Flander, K., Gommans, L., \& Broers, W. (2011). designing for only energy: Suboptimisation. Paper presented at the PLEA 2011, Louvain-la-Neuve, Belgium.

Rovers, V., Rovers, R., de Flander, K., Broers, W., Houben, J., Gommans, L., \& Sigwarth, S. (2011). Maxergy, duurzaamheidsbereking op basis van landgebruik: RiBuilT / Zuyd University of Applied Sciences.

Stephan, A., Crawford, R. H., \& de Myttenaere, K. (2012). Towards a comprehensive life cycle energy analysis framework for residential buildings. Energy and Buildings, 55(0), 592-600. doi: http://dx.doi.org/10.1016/j.enbuild.2012.09.008

Stephan, A., Crawford, R. H., \& de Myttenaere, K. (2013). A comprehensive assessment of the life cycle energy demand of passive houses. Applied Energy, 112(0), 23-34. doi: http://dx.doi.org/10.1016/j.apenergy.2013.05.076

Thormark, C. (2007). Energy and resources, material choice and recycling potential in low energy buildings. Paper presented at the ClB conference SB07 Sustainable Construction, Materials and Practices Lisbon, Portugal.

Torcellini, P., Pless, S., Deru, M., \& Crawley, D. (2006). Zero Energy Buildings: A Critical Look at the Definition. Paper presented at the ACEEE Summer Study, California.

Tran, H. T. (2009). measuring sustainability: Carbon or land? Paper presented at the iNTA-SEGA.

VABI. (2013). VABI 114 website. from http://www.vabi.nl/Producten/Vabi-Uniforme-Omgeving/Gebouwsimulatie

Verbeeck, G., \& Hens, H. (2010). Life cycle inventory of buildings: A contribution analysis. Building and Environment, 45(4), 964-967. doi: 10.1016/j.buildenv.2009.10.003

Yohanis, Y. G., \& Norton, B. (2002). Life-cycle operational and embodied energy for a generic single-storey office building in the UK. Energy, 27(1), 77-92. doi: http://dx.doi.org/10.1016/S0360-5442(01)00061-5

Zadelhoff. (2013). Nederland compleet; kantoren en bedrijfsruimtemarkt. 